\title{
Case Sensitive? A review of the literature on the use of case method in entrepreneurship research
}

\section{Introduction}

This paper focuses on the use of case study in entrepreneurship research. Case study has been deemed a suitable research strategy when the proposed research is exploratory, involves a novel and contemporary phenomenon, and addresses the 'how' and 'why' questions (Yin, 1994; 2012). An especially valuable dimension of the case approach in the context of entrepreneurship research is that the particular phenomenon under investigation is not isolated from its context; rather, it is of specific interest precisely because it is directly related to its context (Hartley, 1994). Thus, it is often possible to gain a much deeper and richer understanding of phenomena by applying case study rather than other approaches.

Notwithstanding the above, while case method has gained popularity in the Information Systems (IS) literatures (Shakir, 2002), and has long been established as a legitimate research approach in the field of organizational theory (Locke \& Golden-Biddle, 1997), it is still used sparingly in entrepreneurship and small business research. Indeed, as highlighted by Pauwels \& Matthyssens (2004), only a small percentage of empirical papers published in top journals within the field of international management or business research have used qualitative approaches. This could be due to the fact that the field of entrepreneurship has not witnessed the same explosion in the use of qualitative methods that has occurred in almost every other research field within the social sciences (Hindle, 2004). Alternatively, as suggested by Brush (2007: 467), the continued lack of qualitative entrepreneurship scholarship - including casebased research - may be due to the requirement for often detailed and lengthy methodological 
explications, which presents particular difficulties when trying to produce publishable succinct papers within restricted word lengths.

Based on the above, we believe that the use of case method in entrepreneurship research requires further investigation. With this in mind, this paper aims to critically review relevant literatures and offer insights into the use of case method in particular settings. This, in turn, will help lay the foundation for a future research agenda, enabling future scholars to see the value in the case study approach as well as its potential application. Thus, our core research question focuses on how case method has been applied in extant entrepreneurship literatures. To address this, we use a systematic literature review (SLR) to explore published research in the 'big five' entrepreneurship journals over a five-year period. While our review highlights incidents where case method has been used successfully, it also identifies areas were case application might be strengthened, and in this regard, offers valuable learning to future case researchers. We argue that case method is not used frequently in entrepreneurship research because it is not yet fully accepted as a legitimate research approach. Our study contributes to entrepreneurship scholarship from both a methodological and theoretical perspective by furthering our understanding of the use of case method in entrepreneurship research. The findings from this study should be of value to qualitative scholars applying case method in their empirical work, as well as those seeking to extend their methodological reach beyond a purely quantitative orientation.

The next section of the paper lays the foundation for the study by reviewing some of the main scholarly contributions to the case study literature, and discussing case method in the context of entrepreneurship research. The methodology adopted for our study is outlined, and this is followed by a presentation of the findings from our five-year SLR. The subsequent section 
discusses our findings. Finally, some conclusions are drawn, and guidelines for a future 'case' research agenda are offered.

\section{Research Context}

\section{Case method scholarship}

Case study research is a highly qualitative form of inquiry; it typically involves a detailed investigation of one or more organizations (or groups within organizations); draws on data collected over a period of time, and aims to provide an analysis of the context and processes involved in the phenomenon under study. It allows researchers to gather rich and insightful data in the field “face-to-face with real people” (Rossman \& Rallis, 1998: 8). The case approach is both exploratory and inductive; involves either single or multiple cases, and can include a wide range of 'units of analysis' (i.e. individual entrepreneurs, firms, products, processes, etc), contexts and data sources. While a comprehensive discussion on how to use case method is beyond the scope of this paper, by way of laying the foundation for our study, it is appropriate to consider extant case scholarship and its contribution to date. In this regard, Yin's $(1981 ; 1994)$ seminal works on case method are largely recognised as having established the 'ground rules' for developing robust qualitative approaches that offer valuable alternatives to large-scale quantitative scholarship. Yin argues that case method represents a research strategy that may be likened to an experiment, yet employs very specific methods of data collection and analysis. He highlights the particular value of case research when "the boundaries between phenomenon and context are not clearly evident” (Yin, 1981: 59). Further, he ascertains that certain research questions are best addressed by case study as opposed to other methods. In this regard, he draws attention to a particularly complex (but often overlooked) problem facing case researchers, i.e., the fact that context forms an integral 
part of the study. Yin uses the latter point to reinforce the value of case study, because studying context-embedded phenomena typically means that there are too many variables for other research designs to accommodate. This is particularly important in the context of entrepreneurship research, as will be highlighted later in the paper.

Miles \& Huberman's (1994) contribution to case scholarship is noteworthy for its focus on the analysis of case data. They argue that an inductive, iterative approach should be adopted, suggesting that documentary evidence, interview transcripts, supporting notes and the like need to be read and re-read several times to allow key recurrent topics to emerge and be coded. This, in turn, allows for a simple matrix of first order categories to be created, with more focused theoretical dimensions or 'second order' themes subsequently identified and refined (Philips et al., 2013).

More recent case literature, such as that of Perren \& Ram (2004), explores the rationale for the use of case studies in entrepreneurship and small business research. Their review of extant case-based scholarship, while not drawn specifically from an SLR approach, offers valuable insights into the various perspectives adopted by entrepreneurship researchers. Furthermore, their review categorises case method usage, and discusses the various implications of adopting case method. Perren \& Ram's key contribution lies in the paradigmatic map they construct to illustrate the range of paradigms underlying case study research in small business and entrepreneurship. The authors distinguish between 'objective' and 'subjective' perspectives, 'milieu' and 'entrepreneurial' boundaries, and the 'organisation' and the 'entrepreneur' as separate and distinct units of analysis, highlighting the fact that case studies may involve several different actors each with their own unique perspective. While acknowledging that no single paradigmatic approach is ideal, their conceptualisation is 
intended to "sensitize researchers to the plurality of case study paradigms and therefore provide some form of release from the hegemony of a particular paradigmatic cage” (Perren \& Ram, 2004:95). The present paper aims to build on this research by offering insights into the use of case method in particular entrepreneurial settings.

\section{Using case study method in entrepreneurship research}

While still used relatively sparingly in entrepreneurship research, case method has been applied across a range of entrepreneurial contexts including, but not limited to, family business (Khavul et al., 2009), entrepreneurial networking (Jack et al., 2008), entrepreneurial teams (Iacobucci \& Rosa, 2010), innovation (Vega et al., 2012; Johnston et al., 2010), leadership (Kansikas et al., 2012), small business support (Mole \& Keogh, 2009) and social enterprise (Haugh, 2007; Vickers \& Lyon, 2012). The case approach has also been shown to be especially suited to particularly complex entrepreneurial contexts; for example, Simmons (2008) rationalizes the use of case method in his exploration of cross-sector social partnerships' (CSSPs) delivery of local public services, contending that the qualitative case approach allows one to "see how issues work out in practice" (p.282). Furthermore, Lewis (2013) uses a single case approach to explore the hidden drivers behind the entrepreneurial non-profit volunteer student army created in the aftermath of the Christchurch earthquake disaster in New Zealand. In such contexts, quantitative methods would simply not have yielded the depth of insight required to better understand the particular topic or problem under investigation; rather, consistent with Yin (1981), applying case method in these situations helped accommodate the blurred boundaries between phenomenon and context (p. 59). 
Case method has been deemed especially appropriate when exploring new entrepreneurial topics or novel examples, particularly in instances where existing theory seems inadequate (see, for example, Bagnoli \& Megali, 2011; Corner \& Ho, 2010). However, it is especially valuable when developing and refining entrepreneurship theory, and is, essentially, a research strategy focused “on understanding the dynamics present within single settings” (Eisenhardt, 1989: 534). Indeed, Eisenhardt's scholarship represents an important step forward in the development of case method, sophisticating and legitimising its standing by illustrating how testable, valid and reliable theories can be derived from highly qualitative case approaches. Of particular relevance to entrepreneurship research is Eisenhardt's highlighting of case method's potential for generating novel theory, and the inherent value of 'paradoxical evidence' (p.546). In this regard, it is, according to Eisenhardt, the researcher's attempts to constantly compare (Silverman, 2000) and reconcile evidence across different cases, data types, investigators and literatures that almost forces him/her to 'unfreeze' thinking, and thus increases the potential for the development of a creative (entrepreneurial) theory.

\section{Challenges and criticisms of case method research}

Despite the value that the case approach clearly brings to entrepreneurship and small business research, it has been heavily criticised in the literature, and this, in part, has led to its sparing application in published entrepreneurship scholarship. Indeed, as highlighted by Ogbar (2000), entrepreneurship research has traditionally used positivist methods, which to some extent has prevented the field moving beyond its quantitative orientation and adoption of functionalist paradigms (Eriksson \& Kovalainen, 2008). Such critically unchallenged adherence to positivism appears to derive from the constant requirement for qualitative approaches to demonstrate that their research is credible. In this regard, a number of commentators have attempted to establish procedures for establishing validity in qualitative 
research, including but not limited to triangulation, peer reviews, external audits and thick description (Wallendorf \& Belk, 1989; Snow \& Anderson, 1987; Creswell \& Miller, 2000). However, it was Guba and Lincoln $(1982 ; 1994)$ who essentially laid the ground rules for ensuring trustworthiness in qualitative scholarship, articulating these in terms of: credibility, transferability, dependability and confirmability. Credibility typically deals with internal validity, and concerns the multiple realities that the researcher has to deal with. Transferability is related to external validity and is concerned with the generalizability of findings based on the robustness of the sample. While dependability deals with the issue of replicability, confirmability concerns the objectivity of the data. Further, Guba and Lincoln (1982: 247-248) offer several strategies for overcoming the above issues, including: prolonged engagement at a research site, persistent observation, theoretical sampling, referential adequacy materials and triangulation. With specific regard to entrepreneurship and small firms' research, it has been suggested that grounded data gathered by ethnographic approaches can be especially useful in countering trustworthiness and validity criticisms (Stockport \& Kakabadse, 1981; Hill \& Wright, 2001). As demonstrated in our review findings presented later in this paper, such 'credibility-safeguarding' strategies can be especially valuable in countering the criticisms of case study research, and could help address the apparent reluctance of journal editors to publish such scholarship.

Other criticisms of case method include the perception that one cannot generalize from case studies, especially single cases, as it is claimed that they do not provide reliable information (Abercrombie et al, 1984; Giddens, 1984; Yin, 1994). There are also issues around case selection, analysis and reporting that consistently come under scrutiny - perhaps (unfairly) to a greater degree than in other methodological approaches - but that scholars such as Yin (1994), Miles \& Huberman (1994) and Patton (2003) have endeavoured to rectify. By way of 
refute of such criticisms, Flyvgjerg (2006) offers counter arguments for the five most common 'misunderstandings' about case study research: that theoretical knowledge is more valuable than practical knowledge; that single case studies cannot contribute to scientific development because one cannot generalise from them; that case studies are useful for generating hypotheses rather than theory building; that the case approach is biased toward verification, and that it is difficult to summarize specific case studies. Flyvberg's support for the case approach is grounded in its 'closeness' to real-life situations, its proximity to the study of reality, and its multiple wealth of detail (2006: 223). He particularly values the learning that can be gained from case research, arguing that distance from the object of study and lack of feedback - (which, the authors note, is more likely to occur with quantitative approaches) - can lead to academic blind alleys where the usefulness of the research becomes unclear (p.223). As a strong proponent of the case approach, Flyvbjerg argues that case study is both a necessary and sufficient method for certain research tasks within social sciences, but despite it 'holding up well' to other research methods within the field, it continues to be disadvantaged in favour of large samples (p. 242).

\section{Methodology}

\section{Approach}

A systematic literature review (SLR) was employed for the study (see Table 1). According to Pittaway \& Cope (2007), SLRs are now well established as appropriate methodological approaches within the field of entrepreneurship research, and are especially useful where large volumes of evidence over long time periods are involved (Denyer \& Neeley, 2004). SLRs involve several steps, namely: identifying relevant work, assessing the quality of studies, summarising the evidence and interpreting findings (Khan et al., 2003). Rather than 
conduct a general Boolean search across the broad entrepreneurship literatures, it was decided to restrict the review to a particular set of journals, i.e. the 'big five' in entrepreneurship research ${ }^{1}$. The reasoning behind this approach was two fold: firstly, restricting the search in this way ensured that the resulting hits were limited from the outset, reducing the need for significant additional filtering. Secondly, consistent with Katz (2003) and Brush (2007), the 'big five' are considered the premier journals for publishing contemporary robust entrepreneurship scholarship, so exploring the extent to which articles employing case method are published in these journals offers an indication of how case method is perceived by the 'academy.'

We conducted our 'within-journal' searches through Business Source Complete using a systematic Boolean keyword search including the terms: (case study OR case method) AND (entrepreneurship OR entrepreneur OR enterprise OR small business OR small firm OR new venture creation) in the 'Abstract' and subsequently in the 'All Text' fields. The search strings were developed by the authors based on their initial literature review. The supplement of 'All Text' fields was added to the search strings because initial searches showed that not all of the abstracts described the methodological approach in sufficient detail, or did not use the term 'case' even when it became clear that the methodological approach used was casebased.

Our review covered the five-year period between January 2008 and December $2012^{2}$, and focused only on empirical papers. Exclusions included special issue editorials, conceptual papers as well as teaching cases, the latter constituting an entirely separate genre of case

\footnotetext{
${ }^{1}$ Journal of Business Venturing (JBV); Journal of Small Business Management (JSBM); Small Business Economics; Entrepreneurship \& Regional Development; Entrepreneurship Theory \& Practice.

${ }^{2}$ While we acknowledge that five years may be perceived as a relatively short period, it was felt that, given our proposed scope and depth of analysis, a longer time period would be unmanageable.
} 
study with significant practical rather than theoretical value (see, for example, Christensen \& Hansen, 1987). A final total of 52 articles were included in the review.

\section{Analysis}

Drawing on Ahl (2002), and Henry et al. (2013), amongst others, the authors constructed a thematic reading guide and devised an appropriate coding system. The reading guide focused on the particular research topic under investigation in each of the articles, the number of cases involved, the unit of analysis, the case source, the nature of the data gathered and the type of case analysis conducted. The particular country and sector on which the case was based was also noted (see Table 2). Consistent with Neergaard et al. (2011:8), as cited in Henry et al. (2013), the authors decided early on in the SLR process to use a manual coding system because not all of the variables explored were 'explicit' or 'clear-cut', and thus required reading, re-reading and additional reflection on the part of the authors. Table 3 presents snippet samples of some of the evidence collected from the SLR, while Table 4 summarises the number of papers published per year by each journal. The data from our fiveyear/five-journal SLR were analysed and combined into a master spread-sheet to identify longitudinal trends and key correlations, the latter using SPSS. Our analysis of the data also allowed us to critique the dominant themes emerging from our SLR, highlight how they contribute to and challenge extant debates, and finally identify areas worthy of future research.

The next section presents the findings from our review of the 52 published research articles selected for our SLR. 


\section{Findings}

Key research topics

Consistent with Perren \& Ram (2004), and Yin (2012), our SLR revealed a wide range of research topics and contexts in which case method has been applied, with the most popular being 'networking' (10 papers), followed by 'regional development' (7) and 'social enterprise' (7). 'Family business' (4) also featured, as did 'innovation', 'clustering', 'support' and 'gender', the latter four topics each attracting three case papers. The remainder of the papers covered topics as diverse as teams, incubation, marketing, institutional frameworks, finance and technology transfer, among others. While there were only a few papers covering these latter topics, the application of case method here reflects, perhaps, the longstanding perceived appropriateness of the case approach to exploring emerging or novel research phenomena (Yin, 1994).

The 'networking' papers in our SLR appeared to use case method to explore issues such as 'how entrepreneurial networks change and develop over time' (Jack et al., 2008); 'how organisations use their internal networks to innovate' (Kelley et al., 2009), and 'how regional communities of practice are developed through networking' (Gausdal, 2008). In this regard, the SLR analysis also revealed that the networking phenomenon was investigated using several different units of analysis within the particular case setting, including network members/entrepreneurs, firms/organisations, individual programmes, cultural groups and regions. This, to some degree, reflects the appropriateness of the case approach to exploring phenomena within rather than separate to their specific contexts (Hartley, 1994; Yin, 1994; 2012). 
The popularity of case studies on 'networking' could potentially be explained by the rise in popularity of the topic generally within the small business research and management literatures (cf. Knights et al., 1993; Mort \& Weerawardena, 2006; Meier \& O'Toole, 2003). However, our study also revealed that the majority of the case based networking papers (8) were published in just one of the 'big five' journals, i.e. Entrepreneurship \& Regional Development. Within such studies, researchers used case method to: demonstrate how networks are vital living organisms that change and grow over time (Jack et al., 2008); show how network reflection influences regional collective learning and increases knowledge linkages (Gausdal, 2008); identify best practice in innovation brokering through the process of networking (Batterink et al., 2010), and highlight the specific drivers that moderate how entrepreneurial networking is practiced across different cultures (Klyver \& Foley, 2012). Given that networking is a context embedded phenomenon, it is unlikely that alternative research approaches would have yielded the same depth of insight (Yin, 1981). Further, as illustrated by Kelley et al. (2009), some phenomena such as networking need to be examined in their natural setting.

\section{Geographical scope and sectorial focus}

Across our five-year SLR period, it was clear that the case studies focused predominately on entrepreneurship phenomena occurring in the 'big three' geographical regions, i.e. the USA/Canada, UK and Australasia $(\mathrm{n}=22)$. While mainland European countries were also included in the case papers, developing countries attracted significantly less case attention, with only a handful of papers contextualised in, for example, India (2), Africa (3) and Bangladesh (1). This is not entirely surprising, given the general underrepresentation of such regions in published scholarship within top tier journals (see, for example, Henry et al., 2013). While the majority of cases in our SLR were based in a single country, almost 20 per cent of 
papers ( $n=9)$ included multi-country studies, such as Kistruck \&Beamish’s paper (2010) on social enterprise (Africa and Latin America), and Parker's (2008) on governance (Switzerland, Ireland and Australia); this perhaps reflects a growing trend toward cross country comparison, and supports the long-held view that multiple rather than single case approaches are considered to be more robust because they potentially increase the methodological rigor of the study (Miles \& Huberman, 1994), and aid theory building (Corner \& Ho, 2010).

With regard to sectorial focus, the majority of the cases drew on single sector settings, with ICT being the most popular (7 papers), followed by technology (6), social (5) and agriculture (3). This reflects the depth of focus associated with the case approach. However, similar to the trend revealed in relation to geographical focus, almost 20 per cent of the case settings were contextualised across multiple sectors, such as in the study by Lechner and Leyronas (2009) on entrepreneurial teams in the diversified services, food and consulting sectors in France, and in the paper by da Rocha et al. (2009) on innovation clusters in the furniture and clothing sectors in Brazil. A notable exception to the traditional case geographical/sectorial setting evident in our analysis was the case paper by Cahn (2008), which explored indigenous micro-entrepreneurship in Samoa's craft and agricultural sectors. All of this demonstrates the diversity of case application in entrepreneurship research, as well as its considerable crosscomparative value.

\section{Case design}

The case papers analysed in our SLR adopted both single and multiple case designs, although around one third of the studies used only one case. Across all 52 case papers, the average number of cases involved was 4 , and the largest was 15 . With regard to the latter, Clark 
(2009) used multiple cases to conduct an in-depth exploration of entrepreneurship and diversification on English farms. While his multiple, cross-case comparative approach demonstrated that entrepreneurially diversified businesses derive economic benefit, his rich insights revealed two important issues militating against an EU policy that encourages entrepreneurship amongst farmers: first, that on-farm innovation depends on informal networks, and second, that CAP (Common Agricultural Policy) structures are viewed unfavourably by farmers.

Within individual case designs, a wide variety of perspectives were critiqued, with units of analysis spanning micro, meso and macro contexts. The 'firm' was by far the most popular unit of analysis ( $\mathrm{n}=19$ ), followed by the ‘individual/entrepreneur' (9), 'city/region’ (7) and ‘organisation' (4). Less traditional units explored within the SLR case papers included a 'set of relationships', 'processes', 'episodes' and 'clusters'. This demonstrates the highly qualitative and versatile nature of case method, and provides evidence of its potential for investigating non-static, intangible phenomena. Particularly noteworthy in this regard were papers by Perrini et al. (2010), and Corner and Ho (2010), which critically explored entrepreneurial processes and social episodes, respectively, each in the context of social enterprise. Interestingly, both papers adopted opportunity recognition as the theoretical lens through which they: illustrate - through an in-depth case study of a single drug-rehabilitation community in Italy - the need for consistency between individual, organisational and contextual dimensions (Perrini et al., 2010), and demonstrate - through the exploration of three innovation episodes in the agricultural sector in New Zealand - how it is multiple rather than individual actors who bring social opportunities to fruition (Corner \& Ho, 2010). These studies demonstrate the particular suitability of the case approach to the study of social enterprise, supporting the view that intertwinement of both phenomena and context (Hartley, 
1994, and proximity to the subject under investigation (Flygjerg, 2006) demand such an approach.

\section{Data and analysis}

In analysing the case papers in our SLR we sought to explore the nature and quantity of the data gathered within case settings, and to identify the various data analysis methods employed. With regard to the former, we found an extensive variety of data types, which we coded accordingly. In addition to the traditional data collection 'tools' employed in qualitative empirical studies, i.e. interviews, observations and site visits, all of which predominated in the case papers we reviewed ${ }^{3}$, we also found ethnography (3 papers), workshops (1), field trips (1) and meetings (1). Seven of the case papers adopted a longitudinal research design, which allowed the various entrepreneurship phenomena to be critically explored over time. (See, for example, Drori et al., 2009, who used longitudinal case design to explore changes in the lifecycle of an internet firm in the US, and West et al., 2008, who studied changes in economic development over time in Latin America).

Although implicit in case design method, contrary to Guba and Lincoln (1982), the use of documentary evidence was explicitly stated as a data source in only half of the papers in our SLR. Even then, the exact type, scope or quality of the documentation involved was not always specified, and in some cases, the nature of the documentation and, indeed, its source, appeared vague or its relevance was unclear. Notable exceptions in this regard include the case study papers by Perrini et al. (2010), who, amongst other data sources, used archival data, magazines and annual reports as the foundation for their exploration of social enterprise processes in San Patrignano; Marchisio et al. (2010) who drew on family letters and

\footnotetext{
${ }^{3}$ Interviews were used in all but six of the case papers; sixteen papers used observation.
} 
consultants' reports to investigate corporate venturing in three family businesses in Italy, and da Rocha et al. (2009), who included press articles in their documentary evidence to explore two industry clusters in Brazil. The longitudinal and ethnographic case approaches were used to explore topics such as networks, family business, social enterprise and regional development, and mostly included multiple rather than single case designs.

The type and level of data analysis varied greatly between SLR cases. Again, although mainly implicit in case method design, thematic analysis was stated as being used in just under half of the cases, with coding procedures explicitly referred to in just eighteen cases. Other analytical approaches included frequency analysis, paired analysis and matrices. Analytical software packages were used to analyse interview data in six studies. Specific triangulation measures were referred to in just four cases. While over $60 \%$ of the studies $(n=35)$ employed multiple case designs, less than half of these explicitly employed cross case comparative analysis. Finally, six cases in our SLR purported to be only broadly inductive or simply did not specify the approach they used to analyse their case data.

\section{Discussion}

While making the case for the use of qualitative approaches, including case studies, in entrepreneurship research, Brush (2007: 461) acknowledges the difficulties associated with getting such work published. Her view is supported by the findings of this study, which evidence the limited number of case-based research papers published in top tier journals. Our SLR revealed that less than five per cent of articles published in the "big 5" journals over our five-year review period used case method. Further, it is clear from our study that not all entrepreneurship journals accept case based research, with journals such as SBE and JBV 
publishing the least number of case papers ( 1 and 3 respectively). While ERD ( $n=30)$ and ETP $(n=14)$ published the greatest number of case method papers between 2008 and 2012, there was a noticeable variance in both frequency of publication ${ }^{4}$ and the depth of explanation provided ${ }^{5}$ within the articles regarding how case method was applied.

\section{Source and selection}

Although used relatively sparingly in the entrepreneurship literatures, it is clear from our SLR that case method has been applied in a wide and varied manner within extant scholarship. Indeed, we provide evidence of case usage across different geographical settings and analytical contexts, with applications in both single and multiple forms, employing both typical and extreme case types. A varied and extensive range of data types was used and, in some cases, complex analytical techniques were applied. Despite this, a notable omission in the majority of the case studies included in our SLR was detail around case source and selection. However, it is acknowledged that by their very nature most case studies are 'convenience' in nature, derived from the authors' own networks or personal contacts/knowledge. Furthermore, it could be argued that, although implicit rather than explicit in design, case selection tends to be 'purposive', where authors deliberately seek typical or extreme cases that demonstrate the particular phenomena under investigation and examine them in their 'natural setting' (Kelley et al., 2009: 224). Authors who clearly challenged such design trends include Kistruck \& Beamish (2010) who attribute the source of their ten cases to information derived from several large international funding agencies, and clearly state both their 'purposive' and 'case variance' selection approach in their exploration of social enterprise activity in Africa and Latin America. Similarly, Jack et al. (2008) derive

\footnotetext{
${ }^{4}$ ERD published its greatest number of case papers in $2008(n=9)$, while ETP's highest number of case papers were published in $2010(n=5)$.

${ }^{5}$ We also noted that while both ERD and ETP papers contained a considerable amount of case explanation, generally more detail, especially in relation to data analysis, was included in the case papers published in ETP.
} 
their three cases from a data set of oil service companies operating in the Grampian region of the North East of Scotland, but clearly acknowledge the deliberate purposive nature of their case selection strategy in exploring network processes over time.

\section{Innovative case application}

Our SLR also demonstrates how case method can be applied to innovative entrepreneurial settings to illustrate particularly nuanced or sensitive phenomena, which would be difficult to robustly explore by means of quantitative data alone. Notable examples in this regard include the case approach adopted by Corner \& Ho (2010) to critically explore a series of multiple 'episodes' in the agricultural social enterprise sector in New Zealand. Their embedded case study, comprising case history construction and cross 'episode' analysis, facilitated an indepth exploration of how opportunities develop in social entrepreneurship. Here, the case approach allowed them to illustrate how social 'actors' begin by seeing a social need and then 'prospect' ideas that they feel could potentially address that need. Furthermore, they demonstrate how it is typically not one but several actors who are involved in bringing social ideas to fruition. Similarly, McAdam \& Marlow (2011) use the single case setting of an incubator in Southern Ireland to uncover the valuable role that client advisors play in developing tenant business plans for investment readiness. Nuanced perceptions around the investment, gate-keeper and capacity building roles of venture fund managers and the incubator itself are also uncovered; such revelations might not have been possible by means of other empirical methods.

\section{Data analysis}

Our SLR also noted a general lack, in some case papers, of detail around data analysis, with the analytical process involved 'referred to' rather than actually 'reported'. The absence of 
such analytical detail, while to some degree understandable for reasons already articulated by Brush (2007), could serve to undermine the rigour of case research, which could potentially damage its perception, which in turn exacerbates the difficulties associated with getting such research published. Articles that clearly challenge such trends include, for example, the paper by Lutz (2011), who used a longitudinal multiple case research design to explore how local government can help foster entrepreneurship; the study applied both synchronic and diachronic data analysis to demonstrate how procurement strategies can be used by government to engage SMEs in local economic development and generate tangible benefits for local authorities. In a similar vein, Salvatto et al. (2010) used a single case approach drawing on an extensive range of documentary evidence and interviews, and applying detailed open and axial coding, including constant data comparison techniques, to demonstrate how 'inhibitors' of business exit can be transformed into 'facilitators' of change in family business.

Although not included in our SLR, we note that the International Journal of Entrepreneurial Behaviour and Research has published 35 case based papers between 2008 and 2012, representing approximately 19 per cent of its total published articles during that time; this is almost five times the level of case papers published across the 'Big Five', where the number of case studies published therein equated to approximately five per cent of their total published articles.

\section{Conclusions}

This paper aimed to critically review entrepreneurship literatures and offer insights into the use of case method in particular settings. In so doing, we aimed to lay the foundation for a 
future research agenda, enabling future scholars to see the value in the case study approach as well as its potential application. Our core research question focused on how case method has been applied in extant entrepreneurship literatures. To address this, we used a systematic literature review (SLR) to explore published research in the 'big five' entrepreneurship journals over a five-year period.

We have argued that case method is not used frequently in entrepreneurship scholarship because it is not yet fully accepted as a legitimate research approach, a view that is supported by evidence from our SLR. Our findings revealed sparse yet varied application of the case approach across an extensive range of topics and contexts. The papers included in our SLR provided considerable depth of insight and understanding, with researchers using case method where clearly other approaches would not suffice. Novel phenomena and unorthodox units of analysis were explored in these case papers, reflecting the fundamental value of case method as a facilitator of context embedded investigation (Hartley, 1994). However, despite the obvious value of the case approach, there is clear residue from the longstanding case criticism in relation to reliability, generalisability and theory building capability (Abercromie et al., 1984; Giddens, 1984); in this regard, we argue that such criticism is both disproportionate and out-dated. That said, our SLR did reveal some weaknesses in case application, including but not limited to lack of detail around data type, source and analysis.

The fact that relatively few articles published in the 'big five' entrepreneurship journals use case method, despite repeated calls in the literature for more in-depth, qualitative approaches, potentially suggests that case method is not accepted as a sufficiently rigorous approach in the upper echelons of contemporary published entrepreneurship scholarship. Thus, we argue for greater acceptance of the use of case method amongst the academic community. 
Reflecting Hartley (1994) and Yin (2012), we suggest that entrepreneurship scholars should learn to study entrepreneurship as conditioned by its context. While the findings from our study illustrate how the case study approach can facilitate this, they also show, perhaps, that entrepreneurship scholars are not sufficiently versed in case method application and, as a result, many case-based studies lack some of the essential methodological components that scholars from other disciplines take for granted. If the case study approach is to be afforded the legitimacy it deserves, young scholars need to equipped with the necessary case study/case analysis skills as part of their undergraduate and doctoral education. Furthermore, established senior scholars holding important roles as journal editors need to take responsibility for publishing case study research. Only then, can the field of entrepreneurship really move forward.

This paper builds on extant literatures by furthering our understanding of the use of case method in entrepreneurship research. Thus, it should be of value to qualitative scholars applying case method in their empirical work, as well as those seeking to extend their methodological reach beyond a purely quantitative orientation.

\section{Toward a future research agenda}

In order to set a future research agenda that allows entrepreneurship research to be more thoroughly informed by case study approaches, we argue that the field of entrepreneurship must be prepared to learn from disciplines with longer traditions of case method. Entrepreneurship scholars have much to gain by learning how organizational and sociological scholars employ case studies. For example, organization theory is a field where the case study approach is already deemed to be highly legitimate and where researchers have worked explicitly to demonstrate how case studies must be organized in order to contribute to theory 
(Locke \& Golden-Biddle, 1997). Our primary message for entrepreneurship researchers, therefore, is that they endeavour to understand the rhetorical dimension, i.e., the careful crafting of arguments to persuade an audience. In this regard, we argue that case studies go beyond the mere presentation of data or obvious facts, for, as Lock \& Golden-Biddle (1997: 1060) explain: texts do not simply array "facts” and evidence logically. Rather, case studies in entrepreneurship contribute scientifically when the persuasive practices are woven into the texts. Indeed, a key strength of the case study approach is its ability to construct knowledge that is sophisticated, insightful, reasoned and creative (Locke \& Golden-Biddle, 1997). Our review demonstrates that, in this regard, there is still more work to be done.

We acknowledge that many of the case papers in our SLR had flaws with regard to rationalizing the case source and method of selection. Furthermore, weaknesses were apparent in relation to the method of data analysis and triangulation. To address this shortcoming, future scholars should aim to employ some of the classic tools used in case study research in other disciplines, i.e., how to build better stories and better constructs by comparative logic (Eisenhardt, 1991), bridge quantitative and qualitative logics (Shah \& Corley, 2006), use multiparadigm approaches (Gioia \& Pitre, 1990), and incorporate simulation approaches (Davis et al., 2007). In other words, entrepreneurship scholars can render the case approach more legitimate by employing the scientific tools established by case study researchers in other disciplines.

Overall, our findings highlight a fundamental problem - that case method is still not fully accepted as a legitimate research approach within the upper echelons of published entrepreneurship scholarship. We unashamedly attribute this to journal editors' continued, yet mis-placed sensitivity to the notion that case method is not always perceived by reviewers to 
have the same degree of rigour as the more traditional quantitative approaches. Further, we encourage editors, reviewers, journal communities and doctoral training programmes to incorporate more plurality into the field of entrepreneurship (cf Easterby-Smith et al., 2008). However, more critically, we explicitly challenge journal editors to acknowledge that, as our paper has demonstrated, there are particular research questions, contexts and phenomena that clearly require a case approach, especially those that seek to study context-embedded phenomena where there are simply too many variables for other research designs to accommodate (Yin, 1981). If the case study approach continues to be excluded from top journals - because it is incorrectly deemed to be lacking in reliability and generalizability, or is unfairly criticised in terms of its theory building capability - then there is a risk that novel entrepreneurial phenomena will not get published, and the field of entrepreneurship will not move forward. We posit that journal editors - who have a critical role to play in developing the field - can avoid this by simply recruiting experienced case method editorial board members and reviewers; in addition, where required, specific journal guidelines should be amended to accommodate more robust explanations of case based approaches in the methodology section of submitted papers. Finally, we conclude that it is time for case study research to be afforded the same degree of trust as that continuously and uncritically afforded to quantitative studies. 


\section{References}

Abercrombie, N., Hill, S. \& Turner, B.S. (1984) Dictionary of Sociology, Harmondsworth, UK: Penguin.

Ahl, H. J. (2002) The Making of the Female Entrepreneur: A discourse analysis of research texts on women's entrepreneurship, Jonkoping International Business School, JIBS Dissertation Series No. 015.

Bagnoli, L. \& Megali, C. (2011) ‘Measuring Performance in Social Enterprises’, Nonprofit \& Voluntary Sector Quarterly, 40(1), 149-165.

Batterink, M., Wubben, E.F.M., Klerkx, L. \& Omta, S.W.F. (2010) Orchestrating Innovation Networks: The case of innovation brokers in the agri-food sector, Entrepreneurship \& Regional Development, 22(1): 47-76.

Brush, C.G. (2007) Avoiding a Strike-out in the First Innings. In H. Neergaard \& J. Parm Ulhoi (Eds), Handbook of Qualitative Research Methods in Entrepreneurship, Cheltenham, UK: Edward Elgar: 460-476.

Cahn, M. (2008) Indigenous Entrepreneurship, Culture and Micro-Enterprise in the Pacific Islands: Case studies form Samoa, Entrepreneurship \& Regional Development, Jan, 1-18.

Christensen, C.R. \& Hansen, A.J. (Eds) (1987) Teaching and the Case Method, Boston: Harvard Business School Press. 
Clark, J. (2009) Entrepreneurship and Diversification on English Farms: Identifying business enterprise characteristics and change processes, Entrepreneurship \& Regional Development, 21(2): 213-236.

Corner, P.D. \& Ho, M. (2010) ‘How Opportunities Develop in Social Entrepreneurship’, Entrepreneurship Theory \& Practice, July, 635-659.

Creswell, J.W. \& Miller, D.L. (2000) ‘Determining Validity in Qualitative Inquiry’, Theory into Practice, 39(3): 124-130.

Da Rocha, A., Kuru, B. \& Monteiro, J. (2009) The Difussion of Exporting in Brazilian Industrial Clusters, Entrepreneurship \& Regional Development, 21(5-6): 529-552.

Davis, J.P., Eisenhardt, K.M \& Bingham, C.B. (2007) Developing Theory Through Simulation Methods, Academy of Management, 32(2): 480-499.

Denyer, D. \& Neeley, A. (2004) Introduction to Special Issue: Innovation and productivity performance in the UK. International Journal of Management Reviews, 5-6 (3-4): 131-135.

Drori, I., Honig, B. \& Sheaffer, Z. (2009) The Life Cycle of an Internet Firm: Scripts, legitimacy and identity, Entrepreneurship \& Regional Development: 715-738.

Easterby-Smith, M., Golden-Biddle, K. \& Locke, K. (2008) Working with Pluralism: Determining Quality in Qualitative Research, Organizational Research Methods, 11: 419-428. 
Eisenhardt, K.M. (1989) Building Theories from Case Study Research, Academy of Management Review, 14(4): 532-550.

Eisenhardt, K.M. (1991) Better Stories and Better Constructs: The case for rigor and comparative logic, Academy of Management Review, 16(3): 620-627.

Eriksson, P. \& Kovalainen, A. (2008) Qualitative Methods for Business Research, London: Sage Publications.

Flyvbjerg, B. (2006) Five Misunderstandings about Case Study Research, Qualitative Inquiry, 12(2): 219-245.

Gausdal, A.H. (2008) Developing Regional Communities of Practice by Network Reflection: The case of the Norwegian electronics industry, Entrepreneurship \& Regional Development, 20, May: 209-235.

Giddens, A. (1984) The Constitution of Society: Outline of the theory of structuration, Cambridge, UK: polity Press.

Gioia, D.A. \& Pitre, E. (1990) Multi Paradigm Perspectives on Theory Building, Academy of Management Review, 15(4): 584-602.

Guba, E.G. \& Lincoln, Y.S. (1982) Epistemological and Methodological Bases of Naturalistic Inquiry, Educational Communication and Technology, 30(4): 233-252. 
Guba, E.G. \& Lincoln, Y.S. (1994) Competing Paradigms in Qualitative Research, in N.K. Denzin \& Y.S. Lincoln (Eds), Handbook of Qualitative Research, Thousand Oaks, CA: Sage: 105-117.

Hartley, J.F. (1994) Case studies in organizational research, in Cassell, C. \& Symon, G. (1994) Qualitative Methods in Organizational Research, Sage: London.

Haugh, H. (2007) Community-led Social Venture Creation, Entrepreneurship Theory \& Practice, 1042-2587.

Henry, C., Foss, L. \& Ahl, H. (2013) Parallel Lines? A thirty-year review of methodological approaches in gender \& entrepreneurship Research. Paper presented at the Institute for Small Business \& Entrepreneurship Conference, Cardiff, 12-13 ${ }^{\text {th }}$ November.

Hill, J. \& Wright, L.T. (2001) A Qualitative Research Agenda for Small to Medium-Sized Enterprises, Marketing Intelligence \& Planning, 19(6): 432-443.

Hindle, K. (2004) Choosing Qualitative Methods for Entrepreneurial Cognition Research: A canonical development approach, Entrepreneurship Theory \& Practice, 14(4): 7-14.

Iacobucci, D. \& Rosa, P. (2010) The Growth of Business Groups by Habitual Entrepreneurs: The role of entrepreneurial teams, Entrepreneurship Theory \& Practice, March, 351-377. 
Jack, S., Drakopoulou Dodd, S. \& Anderson, A.R. (2008) Change and the Development of Entrepreneurial Networks Over Time: A processual perspective, Entrepreneurship \& Regional Development, 125-159.

Johnston, L., Robinson, S. \& Lockett, N. (2010) Recognising Open Innovation in HEIIndustry Interaction for Knowledge Transfer and Exchange, International Journal of Entrepreneurial Behaviour \& Research, 16(6).

Kahn, K.S., Kunz, R., Kleijnen, J. \& Antes, G. (2003) Five Steps to Conducting a Systematic Review, J. R. Soc. Med., Mar, 96(3): 118-21.

Kansikas, J., Laakkonen, A., Sarpo, V. \& Kontinen, T. (2012) Entrepreneurial Leadership and Familiness as Resources for Strategic Entrepreneurship, International Journal of Entrepreneurial Behaviour \& Research, 18(2).

Katz, J. (2003) Core Publications in Entrepreneurship and Related Fields: A guide to getting published, version 4.1.1, available from: http://eweb.slu.edu/booklist.htm.

Kelley, D.J., Peters, L. \& Collarelli O’Connor, G. (2009) Intra-Organizational Networking for Innovation-Based Corporate Entrepreneurship, Entrepreneurship \& Regional Development, 24: 221-235.

Khavul, S., Bruton, D.G. \& Wood, E. (2009) Informal Family Business in Africa, Entrepreneurship Theory \& Practice, Nov, 1219-1238. 
Kistruck, G.M. \& Beamish, P.W. (2010) The Interplay of Form, Structure and Embeddedness in Social Intrapreneurship, Entrepreneurship Theory \& Practice, July.

Klyver, K. \& Foley, D. (2012) Networking and Culture in Entrepreneurship, Entrepreneurship \& Regional Development, 24(7/8): 561-588.

Knights, D., Murray, F. \& Willmott, H. (1993) Networking as Knowledge Work: A study of strategic interorganizational development in the financial services, Journal of Management Studies: 30: 6, November

Lechner, C. \& Leyronas, C. (2009) Small Business Group Formation as an Entrepreneurial Development Model, Entrepreneurship Theory \& Practice, May, 645-667.

Lewis, K.V. (2013) The Power of Interaction Rituals: The student volunteer army and the Christchurch earthquakes, International Small Business Journal, 31(7):811-831.

Locke, K. \& Golden-Biddle, K. (1997) Constructing Opportunities for Contribution: Structuring Intertextual Coherence and "Problematizing” in Organizational Studies, Academy of Management Journal, 40 (5): 1023-1062.

Lutz, P. (2011) On the Contribution of Public Procurement to Entrepreneurship and Small Business Policy, Entrepreneurship \& Regional Development, 23(9-10): 787-814. 
McAdam, M. \& Marlow, S. (2011) Sense and Sensibility: The role of business incubator client advisers in assessing high-tech entrepreneurs to make sense of investment readiness status, Entrepreneurship \& Regional Development, 23(7-8): 449-468.

Marchisio, G., Mazzola, P., Sciascia, S., Miles, M. \& Astrachan, J. (2010) Corporate Venturing in Family Business: The effects on the family and its members, Entrepreneurship \& Regional Development, 22(3-4): 349-377.

Meier, K.J. \& O'Toole, L.J.. (2003) Public Management and Educational Performance: The Impact of Managerial Networking, Public Administration Review: 689-699.

Mort, G.S. \& Weerawardena, J. (2006) "Networking Capability and International Entrepreneurship: How networks function in Australian born global firms", International Marketing Review, 23 (5): 549 - 572.

Miles, M. \& Huberman, A.M. (1994) Qualitative Data Analysis. Beverly Hills, CA: Sage Publications.

Mole, K.F. \& Keogh, W. (2009) The Implications of Public Sector Small Business Advisers Becoming Strategy Sounding Boards: England and Scotland compared, Entrepreneurship \& Regional Development, 21(1): 77-97.

Neergaard, H., Frederiksen, S. \& Marlow, S. (2011). The Emperor’s New Clothes: Rendering a feminist theory of entrepreneurship visible. Paper presented at the $56^{\text {th }}$ ICSB Conference, June, Stockholm. 
Ogbar, J.O. (2000) Mythicizing and Reification in Entrepreneurial Discourse: Ideology critiques of entrepreneurial studies, Journal of Management Studies, July: 606-635.

Parker, R. (2008) Governance and the Entrepreneurial Economy: A comparative analysis of three regions, Entrepreneurship Theory \& Practice, Sept, 833-854.

Patton, M.Q. (2003) Qualitative Evaluation and Research Methods ( $3^{\text {rd }}$ ed), Thousand Oaks, CA: Sage.

Pauwels, P. \& Matthyssens, P. (2004) The Architecture of Multiple Case Study Research in International Business, in R. Marschan-Piekkari \& C. Welsch (eds), Handbook of Qualitative Research Methods for International Business, Northampton, MA: Edward Elgar Publishing.

Perren, L. \& Ram, M. (2004) Case-Study Method in Small Business and Entrepreneurial Research: Mapping boundaries and perspectives. International Small Business Journal, 22(1): 83-101.

Perrini, F., Vurro, C. \& Costanzo, L.A. (2010) A Process Based View of Social Entrepreneurship: From opportunity identification to scaling up social change in the case of San Patrignano, Entrepreneurship \& Regional Development, 22(6): 515-534.

Phillips, N., Tracey, P. \& Karra, N. (2013) 'Building Entrepreneurial Tie Portfolios Through Strategic Homophily: The Role of Narrative Identity Work in Venture Creation and Early Growth’, Journal of Business Venturing, 28: 134-150 
Pittaway, L. \& Cope, J. (2007). Entrepreneurship Education: A systematic review of the evidence. International Small Business Journal, 25(5): 479-510.

Rossman, R.B. \& Rallis, S.F. (1998) 'Learning in the Field: An introduction to qualitative research', Thousand Oaks, CA: Sage.

Salvato, C., Chirico, F. \& Sharma, P. (2010) A Farewell to the Business: Championing exit and continuity in entrepreneurial family firms, Entrepreneurship \& Regional Development, 22(3-4): 321-348.

Shah, S.K. \& Corley, K.G. (2006) Building Better Theory by Bridging the Quantitative Qualitaitve Divide, Journal of Management Studies, 43(8): 1821-1835.

Shakir, M. (2002) The Selection of Case Studies: Strategies and their application to IS implementation case studies, Res. Lett. Inf. Math. Sci, 3: 191-198.

Silverman, D. (2000) Doing Qualitative Research: A practical handbook, Thousand Oaks, CA: Sage Publications.

Simmons, R. (2008) ‘Harnessing Social Enterprise for Local Public Services: The Case of New Leisure Trusts in the UK', Public Policy and Administration, 23, 278-301.

Snow, D.A. \& Anderson, L. (1987) Identity Work Among the Homeless: The verbal construction and avowal of personal identities, American Journal of Sociology, 92(May): $1336-1371$. 
Stockport, G. \& Kakabadse, A. (1991) Using Ethnography in Small Firms’ Research, paper presented at UKEMRA Annual Conference, UK.

Vega, A., Brown, D. \& Chiasson, M. (2012) Open Innovation \& SMEs: Exploring policy and the scope for improvements in university-based public programmes through a multidisciplinary lens, International Journal of Entrepreneurial Behaviour \& Research, 18(4).

Vickers, I. \& Lyon, F. Beyond Green Niches? Growth strategies of environmentallymotivated social enterprises, International Small Business Journal, (2014) 32(4): 449-470.

Wallendorf, M. \& Belk, R.W. (1989) Assessing Trustworthiness in Naturalistic Consumer Research, in SV-Interpretive Consumer Research, Eds, Elizabeth C. Hirschman, Association of Consumer Research: 69-84.

West, G.P., Bamford, G.E. \& Marsden, J.W. (2008) Contrasting Entrepreneurial Economic Development in Emerging Latin-American Economies: Application and extensions of resource based theory, Entrepreneurship Theory \& Practice, Jan, 15-36.

Yin, R. K. (1981) The Case Study Crisis: Some answers. Administrative Science Quarterly, 26:58-65.

Yin, R. K. (1994) Case Study Research: Design and methods, $2^{\text {nd }}$ edition, Thousand Oaks:, CA: Sage Publications. 
Yin, R. K. (2012) Applications of Case Study Research, $3^{\text {rd }}$ edition, Thousand Oaks, CA: Sage Publications. 
Case Sensitive? A review of the literature on the use of case method in entrepreneurship research

Colette Henry ${ }^{1}$ (Dundalk Institute of Technology) \& Lene Foss (The Arctic University of Norway)

\section{Abstract}

Purpose This paper seeks to review the use of case method in entrepreneurship research, and to identify trends in its current application. A key objective of the paper is to lay the foundation for a future research agenda by critically reviewing relevant literatures and offering insights into the use of case method in particular settings. The paper also helps identify areas where case method could add value to research findings in future scholarship.

Design/methodology/approach Using a Boolean search, a systematic literature review (SLR) was undertaken across the 'big five' entrepreneurship journals in the five-year period between 2008 and 2012. The search initially yielded a total of 269 'hits'. Following exclusion criteria, the list was refined to a total of 52 empirical papers, and these were reviewed using a comprehensive reading guide developed by the authors.

\footnotetext{
${ }^{1}$ Contact author: colette.henry@dkit.ie
} 
Findings The paper finds that relatively few articles published in the 'big five' entrepreneurship journals use case method, despite repeated calls in the literature for more in-depth, qualitative approaches. This potentially suggests that case method is not fully accepted as a legitimate or sufficiently rigorous approach in the upper echelons of contemporary published entrepreneurship scholarship. Overall the paper argues for greater acceptance of the use of case method amongst the academic community, alongside greater confidence in its application. This can be achieved by learning from other disciplines where the case approach is more established.

Research limitations/implications While a comprehensive systematic literature review was undertaken, the search was restricted to a limited time period and across a limited number of top tier journals.

Practical implications The paper highlights incidents where case method has been used successfully, identifies gaps in the literature and contributes towards setting a future research agenda that should be of particular value to qualitative researchers.

Originality/value The paper builds on extant literatures by furthering our understanding of the use of case method in entrepreneurship research. It should be of value to qualitative scholars applying case method in their empirical work, as well as those seeking to extend their methodological reach beyond a purely quantitative orientation.

Keywords Case method, entrepreneurship, systematic literature review (SLR), qualitative research 
Paper type Research paper 

Table 1. Stages in the SLR process

\begin{tabular}{|c|c|}
\hline Stage & Description \\
\hline 1 & Consistent with Katz (2003) and Brush (2007), the generally recognised 'big 5' journals in entrepreneurship research were selected'. \\
\hline 2 & $\begin{array}{l}\text { The search was restricted to empirically-based articles published in the above journals in the five-year period between } 01 / 01 / 2008 \text { and } \\
31 / 12 / 2012 \text {. }\end{array}$ \\
\hline 3 & $\begin{array}{l}\text { Within-journal searches were conducted through Business Source Complete by means of a systematic Boolean keyword search using the terms } \\
\text { (case study OR case method) AND (entrepreneurship OR entrepreneur OR enterprise OR small business OR small firm OR new venture } \\
\text { creation) in the 'Abstract' and subsequently in the 'All Text' fields. The latter supplement to the search was important because initial searches } \\
\text { showed that not all of the abstracts described the methodological approach in sufficient details, or did not use the term 'case' even when it } \\
\text { became clear that the methodological approach used was case-based. }\end{array}$ \\
\hline 4 & The above combined searches resulted in a total of 269 discrete articles. \\
\hline 5 & $\begin{array}{l}\text { Resulting articles were then examined and the following exclusion criteria applied: calls-for-papers, book reviews, special issue editorials, purely } \\
\text { conceptual articles and teaching cases. Subsequently, more in-depth reading led to us exclude articles where the term 'case' referred merely to } \\
\text { 'incident', or where the author(s) merely commented on case methods used in other studies, or where the term 'case' did not actually mean the } \\
\text { use of case method. This resulted in a final sample of } 52 \text { articles, as follows: } \\
\text { - } \quad \text { Journal of Business Venturing (JBV) [n=3] } \\
\text { - } \quad \text { Journal of Small Business Management (JSBM) }[\mathrm{n}=4] \\
\text { - } \quad \text { Small Business Economics (SBE) }[\mathrm{n}=1] \\
\text { - } \quad \text { Entrepreneurship \& Regional Development (ERD) [n=30] } \\
\text { - } \quad \text { Entrepreneurship Theory \& Practice (ETP) [n=14] }\end{array}$ \\
\hline 6 & $\begin{array}{l}\text { Papers were reviewed using a thematic reading guide (see Table 2) adapted by the authors from Henry, Foss \& Ahl (2013), and previously from } \\
\text { Ahl (2002). }\end{array}$ \\
\hline
\end{tabular}

\footnotetext{
${ }^{1}$ Journal of Business Venturing; Journal of Small Business Management; Small Business Economics; Entrepreneurship \& Regional Development; Entrepreneurshp Theory \& Practice
} 
Table 2. Reading guide

\begin{tabular}{|l|l|}
\hline Category & Details \\
\hline 1. Article title & \\
\hline 2. Author(s) & \\
\hline 3. Year of publication & \\
\hline 4. Journal & \\
\hline 5. Topic & \\
\hline 6. Key research question & \\
\hline 7. Case sample details: & Number of cases involved \\
\hline$\bullet \quad$ Other methods used alongside case & \\
\hline$\bullet \quad$ Case source & \\
\hline$\bullet \quad$ Method of selection & \\
\hline$\bullet \quad$ Country & \\
\hline$\bullet \quad$ Sector & \\
\hline 8. Case method details: & \\
\hline 9. Key findings/conclusions & \\
\hline
\end{tabular}


Table 3. Snippet samples of evidence collected from the SLR

\begin{tabular}{|c|c|c|c|c|c|}
\hline Category & Sample 1 & Sample 2 & Sample 3 & Sample 4 & Sample 5 \\
\hline Article title & $\begin{array}{l}\text { The relationship between knowledge } \\
\text { transfer, top management team } \\
\text { composition and performance: The } \\
\text { case of science-based } \\
\text { entrepreneurial firms }\end{array}$ & $\begin{array}{l}\text { Entrepreneurial orientation } \\
\text { in long-lived family firms }\end{array}$ & $\begin{array}{l}\text { Intra-organizational } \\
\text { networking for } \\
\text { innovation-based } \\
\text { corporate } \\
\text { entrepreneurship }\end{array}$ & $\begin{array}{l}\text { Understanding market- } \\
\text { driving behaviour: The } \\
\text { role of entrepreneurship }\end{array}$ & $\begin{array}{l}\text { Is regional innovation } \\
\text { system development } \\
\text { possible in peripheral } \\
\text { regions? Some evidence } \\
\text { from the case of La } \\
\text { Pocatiere, Canada. } \\
\end{array}$ \\
\hline Author(s) & Knockaert et al. & Zellweger \& Sieger, & Kelley et al. & Schindehutte et al. & Doloreaux \& Dionne \\
\hline Year of publication & 2012 & 2012 & 2009 & 2008 & 2008 \\
\hline Journal & ETP & SBE & JBV & JSBM & ERD \\
\hline Topic & Technology transfer; spin-offs & Family business & Networking & $\begin{array}{l}\text { Entrepreneurial } \\
\text { behaviour }\end{array}$ & Innovation systems \\
\hline Key research question & $\begin{array}{l}\text { Under which conditions does tacit } \\
\text { knowledge transfer contribute to the } \\
\text { performance of academic spin-offs? }\end{array}$ & $\begin{array}{l}\text { What is the nature of } \\
\text { entrepreneurial orientation in } \\
\text { long-lived family firms? }\end{array}$ & $\begin{array}{l}\text { How do project-specific } \\
\text { ties form for non- } \\
\text { routine phenomena? }\end{array}$ & $\begin{array}{l}\text { What is the impact of } \\
\text { market-driving } \\
\text { behaviour on } \\
\text { entrepreneurship? }\end{array}$ & $\begin{array}{l}\text { What are the key actors in } \\
\text { the innovation system in } \mathrm{La} \\
\text { Pocatiere? }\end{array}$ \\
\hline - number of cases & Multiple $(\mathrm{n}=9)$ & Multiple (n=3) & Multiple $(\mathrm{n}=12)$ & Multiple $(\mathrm{n}=2)$ & Single $(n=1)$ \\
\hline - nature of case(s) & $\begin{array}{l}\text { The research institute }+ \text { the spin-off } \\
\text { companies }\end{array}$ & Family firms aged $80-175 \mathrm{yr}$ & Firms & Firms & Region \\
\hline - country & Belgium & Switzerland & USA & USA & Canada \\
\hline - sector & Micro-electronics & $\begin{array}{l}\text { Pharmaceuticals, consumer } \\
\text { goods, printing \& filtration }\end{array}$ & Various & $\begin{array}{l}\text { Engineering + } \\
\text { Beverages }\end{array}$ & Technology \\
\hline - data types used & Interviews + documentary evidence & Interviews & Observation, interviews & $\begin{array}{l}\text { Secondary data, } \\
\text { documentary evidence }\end{array}$ & $\begin{array}{l}\text { Historical data, statistical } \\
\text { data, interviews }\end{array}$ \\
\hline - data analysis & $\begin{array}{l}\text { Iterative analysis - 'back and forth' } \\
\text { from data to literature (consistent } \\
\text { with van Mannen et al; 2007) }\end{array}$ & $\begin{array}{l}\text { Coding, pattern } \\
\text { identification and cross case } \\
\text { comparison }\end{array}$ & $\begin{array}{l}\text { Coding, reliability } \\
\text { checks, cross case } \\
\text { comparison, Nvivo }\end{array}$ & $\begin{array}{l}\text { Thematic analysis } \\
\text { according to: } \\
\text { entrepreneurial } \\
\text { orientation, responsive } \\
\text { market orientation, } \\
\text { proactive market } \\
\text { orientation }\end{array}$ & Descriptive \\
\hline $\begin{array}{l}\text { Key } \\
\text { findings/conclusions }\end{array}$ & $\begin{array}{l}\text { Tacit knowledge is most effectively } \\
\text { transferred when a substantial part } \\
\text { of the original research team joins } \\
\text { the new venture as founders. }\end{array}$ & $\begin{array}{l}\text { Firms exhibited low or } \\
\text { medium levels of the } 5 \\
\text { salient EO dimensions } \\
\text { (autonomy, innovativeness, } \\
\text { risk-taking, pro-activeness, } \\
\text { competitive aggressiveness). }\end{array}$ & $\begin{array}{l}\text { The study identifies } \\
\text { constraints associated } \\
\text { with individual network } \\
\text { capacity at individual, } \\
\text { organisational and } \\
\text { corporate level. }\end{array}$ & $\begin{array}{l}\text { Market-driven } \\
\text { orientation mediates } \\
\text { customer interactions, } \\
\text { while market-driving } \\
\text { orientation mediates } \\
\text { performance. }\end{array}$ & $\begin{array}{l}\text { Size and location did not } \\
\text { hinder the development of } \\
\text { the innovation system; the } \\
\text { region's heritage was an } \\
\text { advantage. }\end{array}$ \\
\hline
\end{tabular}


Table 4. Case-Based Papers Published in Each Journal Per Year

\begin{tabular}{|c|c|c|c|c|c|c|}
\hline Journal Title & & & & & & \\
\hline Publication Year & 2008 & 2009 & 2010 & 2011 & 2012 & Total \\
\hline Journal of Business Venturing (JBV) & 0 & 2 & 1 & 0 & 0 & 3 \\
\hline Journal of Small Business Management (JSBM) & 1 & 0 & 0 & 1 & 2 & 4 \\
\hline Small Business Economics (SBE) & 0 & 0 & 0 & 0 & 1 & 1 \\
\hline Entrepreneurship \& Regional Development (ERD) & 9 & 5 & 6 & 6 & 4 & 30 \\
\hline Entrepreneurship Theory \& Practice (ETP) & 2 & 4 & 5 & 1 & 2 & 14 \\
\hline Total Case Papers Published & 12 & 11 & 12 & 8 & 9 & 52 \\
\hline
\end{tabular}

